\title{
THE RELATIONSHIP OF THE GRAVID PERIODS OF CER- TAIN MUSSELS IN MICHIGAN TO THE PEARL BUTTON INDUSTRY
}

\author{
HeNRY VAN DER Schalie
}

Museum of Zoology, University of Michigan, Ann Arbor, Mich.

In Michigan, the pearl button industry is decidedly limited in its scope. This is largely because of two important factors. In the first place, there are relatively few mussels in the state which can be used commercially. Most important of these are the Mucket (Actinonaias carinata), the Pocketbook (Lampsilis ventricosa), and the Three Rib (Amblema costata). Others of commercial importance are listed in Table 2. In the second place, the species used by the industry are limited in distribution to streams in the southern part of the southern peninsula; i. e., to those streams in the region of and south of the Saginaw-Grand valley. The reasons for this are connected with glacial history and need not be discussed at this time.

Considered in relation to the size of the industry in certain states (such as Wisconsin, Illinois, Indiana, and Ohio), the mussel industry in Michigan has been comparatively small. As in other states it has had a similar history in that at one time mussels were abundant in the more productive streams, but by intensive collecting, pollution in certain areas, power-dam developments, etc., we have reached a stage where mussels for commercial purposes are scarce. In order to give some idea of the present status of the industry in Michigan, the accompanying data ${ }^{1}$ are presented (Table 1 ). From the table we may note the size of the industry in terms of the number of people engaged in gathering the shells, the number of pounds of shell taken, and the value of the raw material. Unfortunately, we do not have for comparison similar figures compiled at a time when the industry was at its best in this state. Such a comparative table would no doubt indicate that the figures for the past five years are but a small fraction of what they once were. For comparison there is, however, a figure in a Bureau of Fisheries Document (972) which lists $4,825,170$ pounds of shell taken from Michigan streams in 1922 , with a value of $\$ 191,161$ (including the value of pearls). Furthermore, there is a statement in the Biennial Report of the Department of Conservation for 1929-1930 (p. 208) which estimates: "The value of the output probably exceeds $\$ 500,000$ annually."

In view of the marked depletion of the mussel population, certain laws ${ }^{2}$ have been enacted presumably with the idea of protecting the "spawning" mussels. These laws provide for open and closed seasons,

These data are taken Prom the Seventh Biennial Report (1933-1934) of the Figh Division of the State Department of Conservation.

2 Lawe Relating to Conservation, State of Michigan, Revision of 1935, pp. 70-73. 
TABLE 1, MUSSELS TAKEN FROM MICHIGAN WATERG

\begin{tabular}{|c|c|c|c|c|c|c|}
\hline & 1930 & 1931 & 1992 & 1999 & 1934 & 1936 \\
\hline $\begin{array}{c}\text { Number of licenses is- } \\
\text { sued }\end{array}$ & 2.460 & 522 & 392 & 822 & 1,362 & 190 \\
\hline $\begin{array}{c}\text { Number of pounts of } \\
\text { shells taken } \ldots \ldots\end{array}$ & $1,753,500$ & $1.503,511$ & $1,543.358$ & $2,950,229$ & 1.746 .623 & $\bullet$ \\
\hline Value of shells $\ldots \ldots$. & $\$ 34.472 .52$ & $\$ 27.376 .06$ & $\$ 21,059.24$ & $\$ 85,309.16$ & $\$ 32,427$ & - \\
\hline$V_{a l u e}$ of slugs and pearls & $\$ 3,206.50$ & $\$ 2,546.64$ & $\$ 884.33$ & $\$ 2,555.55$ & $\$ 1,228$ & $\bullet$ \\
\hline Total ralue & $837,679.02$ & $\$ 20,922.70$ & $\$ 21,943.57$ & $887,864.71$ & $\$ 33,655$ & \\
\hline
\end{tabular}

- Figures not available.

much as such seasons are provided for by fish and game laws. Since there is still mucl to be learned regarding the "spawning" seasons of our freshwater mussels, it would not be surprising to find that closed seasons fixed by law do not actually correspond with the natural spawning period. Data on the gravid periods of Michigan mussels, gathered over a period of several years, have led the writer to the conclusion that it would be of interest to present the available information, and, on the basis of it, to make recommendations which may be wortly of consideration.

The fact that our local species of mussels may be grouped into two major divisions on the basis of their breeding season is generally known. These two groups are referred to in various ways, though essentially the terms have the same meaning. We may refer to one group as shortterm breeders, summer breeders, or tachylictic species; to the other as long-term breeders, winter breeders, or bradytictic species. For convenience we shall refer to them in this paper simply as summer breeders or winter breeders. To define these terms more specifically, the summer breeders propagate usually during some period within the months of May, June, or July; while the winter breeders usually become gravid in late summer and fall, and as a rule carry the larvae (glochidia) through the winter to be set free when the waters become warmer in April, May, or June.

The gravid periods of the mussels of commercial importance in Michigan are shown graphically in Table 2, in which species have been grouped in accordance with the outline just given. The names of three species in this list, namely the Three Rib, the Mucket, and the Pocketbook, have been capitalized, since reports on file at the office of the Conservation Department indicate that these kinds are most desirable for commercial purposes, and constitute the bulk of the shell material gathered each year. As a result, we must consider them of prime importance. From Table 2 we note that the Three Rib is gravid during June and the early part of July. The open season in Michigan does not begin till July, so that this species is perhaps fairly well protected by law. However, the case is quite different when we consider the Mucket and the Pocketbook. They both become gravid early in August, so that 


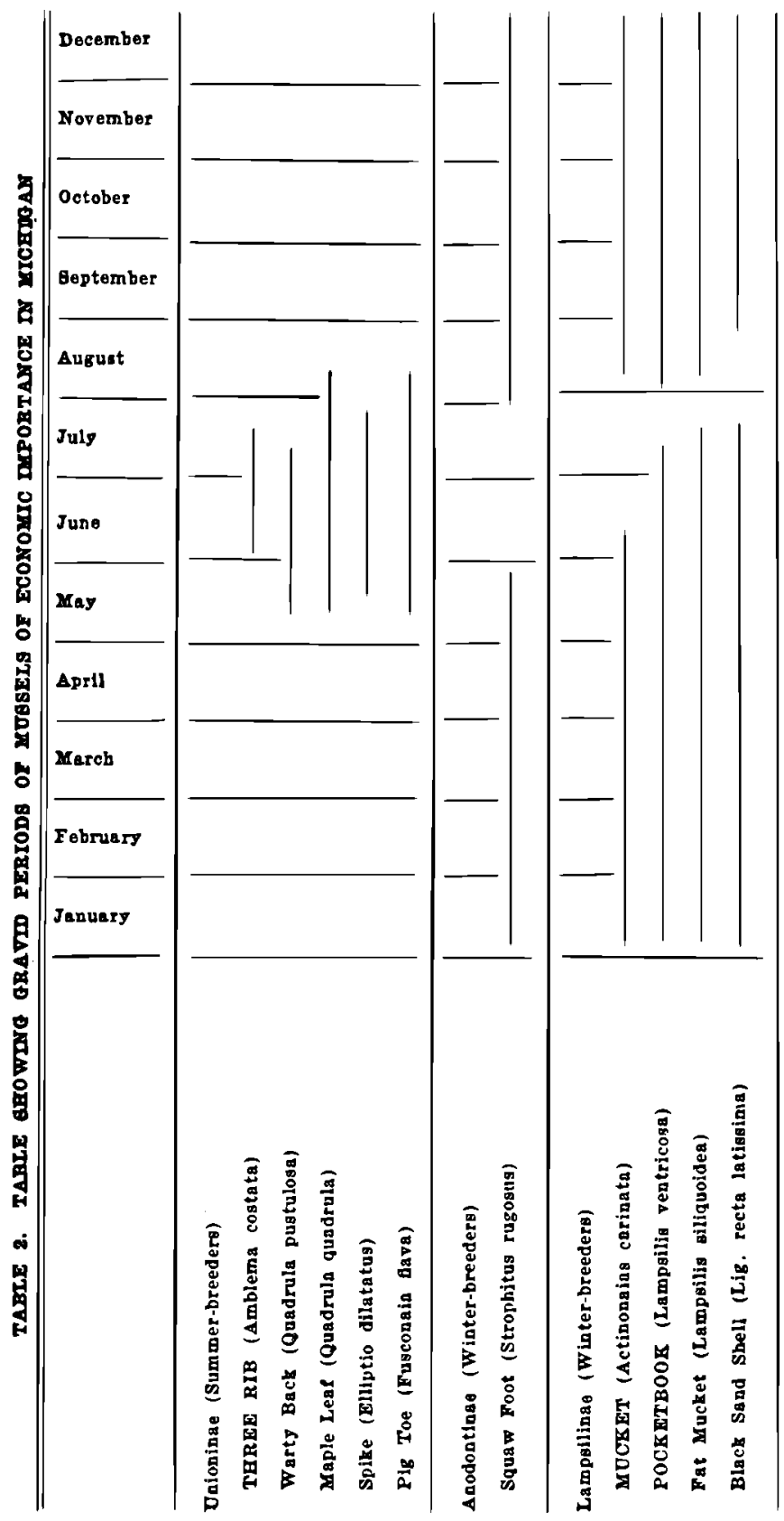


they are not fully protected by the law. In fact, with the open season during the months of July, August, and September, these species are taken in the gravid state during two-thirds of the season. They are of such outstanding importance that it would even seem advisable to protect them without regard to the gravid periods of the other species.

Through the kindness and cooperation of $\mathrm{Mr}$. Fred A. Westerman and his staff at Lansing, permission was granted to examine the annual reports submitted by mussel fishermen operating under state licenses. Because of insufficient time, the reports for 1934 only were considered in detail. The data taken from these 1934 reports may be summarized as follows: of the 1,362 individuals to whom licenses were issued, approximately 542 sent in reports, of which 113 contained statements that would give some indication as to the concensus of opinion among the fishermen on matters pertaining to the industry. Many complained about the small amount paid for the mussels by the buyers. Practically all indicated that the supply had been much depleted, and that as a consequence it was difficult for them to earn sufficient to compensate them for their efforts. A relatively large proportion (fifty-nine out of the 113) felt that this depletion should be remedied by closing the musselproducing streams for a period which varied from three to five years. It was of special interest to find that several suggested that the open season should be shorter, so as to protect the gravid specimens in August and September.

In conclusion, it may be stated that both the scientific information available regarding the gravid periods of mussels of commercial value and such information as has been submitted by the mussel fishermen themselves, indicate that the season for clamming would need to be restricted to the month of July, in order to provide a seemingly adequate protection for the most valuable commercial species during the spawning season.

The conservation measures now applied are apparently based on the assumption that keeping the spawning season closed to clamming sufficiently protects the mussels. If this is true, it is but logical that we curb the open season as indicated above; by limiting that season to the month of July. However, it is very questionable whether such a measure will be effective in conserving the mussels. The perpetuation of organisms that have a life-span of only one or a few years may be insured by protecting the adults during the spawning season. However, in a group, such as the mussels, whose life span is so long that successive batches of young are produced over a period of a considerable number of years, it would likely make but little difference whether adults are taken before, during, or after the breeding season. A mussel taken before the spawning season contains germs of eggs which would probably otherwise have matured during the following spawning season, and also for several years in the future. Destroying these undeveloped eggs is almost as effective as the destruction of the mature spawn. We can go 
even a step farther and question whether closing a stream for a short period (one to five years) would constitute a suitable conservation program for a group that has so long a life-span, and that reaches suitable marketing size as slowly as mussels do; for in so short a period no great amount of growth would result.

The conservation of the nussel supply would seem from the biologist's viewpoint to involve first of all a control of silting and pollution, for the mussels are particularly susceptible to these destructive influences. When regulations are required to maintain a heavily-fished stock, the logical course would seen to be a simple limitation on the quantity that may be cropped in each area without depleting the supply. Deternining the safe crop from year to year would require the services of a trained investigator, who would follow the fluctuations in supply and yield by such methods as are employed in modern fisheries management. He would estimate the population by biological samples, and follow the yield by the analysis of detailed catch records. This would insure the conservation of the fauna and assure the industry of a future. 